\title{
Erratum to: Assessing consistency of Chang'E-1 and SELENE reference frames using nearly-colocated laser altimetry footprint positions
}

\author{
H. Bâki Iz • Y. Q. Chen - C. K. Shum • X. L. Ding • \\ B. A. King - W. Chen $\cdot$ M. Berber
}

Published online: 27 August 2011

(C) Springer-Verlag 2011

Erratum to: J Geod

DOI 10.1007/s00190-011-0495-6

Unfortunately, the strain plots were duplicated in Fig. 3. The correct version of Fig. 3 is given.

The online version of the original article can be found under doi:10.1007/s00190-011-0495-6.

H. B. Iz ( $\varangle)$ · Y. Q. Chen · X. L. Ding · B. A. King · W. Chen

Department of Land Surveying and Geo-Informatics,

The Hong Kong Polytechnic University, Hong Kong, China

e-mail: 1shbiz@polyu.edu.hk

C. K. Shum

Division of Geodetic Science, School of Earth Sciences,

The Ohio State University, Columbus, USA

M. Berber

Department of Civil, Environmental, and Geomatics Engineering,

Florida Atlantic University, Boca Raton, USA 
Fig. 3 The line plot of the twelve estimated deformation parameters (in $\mathrm{m}$ ) from nearly-colocated footprints selected using a combination of different separation distances $(D)$ and radial coordinate differences (dr). Strain and shear parameters are expressed in meters by multiplying them with an average lunar radius. Rotation angles are also expressed as displacements on the lunar surface in meters

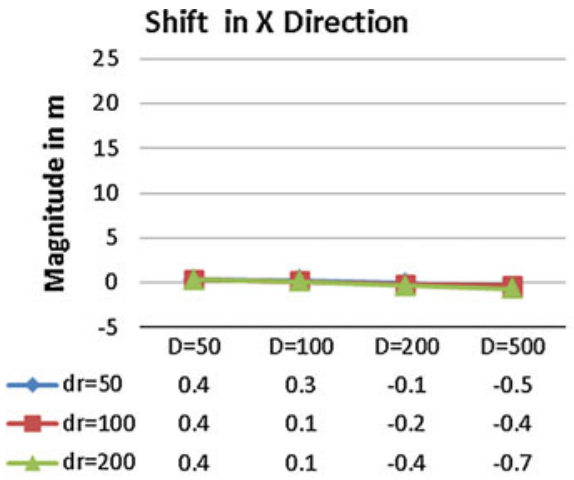

Shift in Y Direction

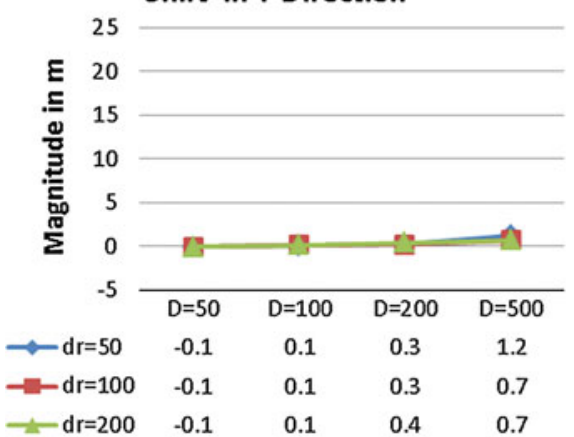

Shift in Z Direction

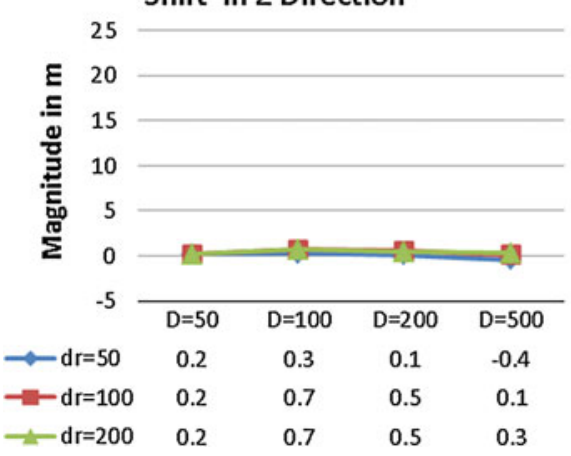

Rotation about X Axis

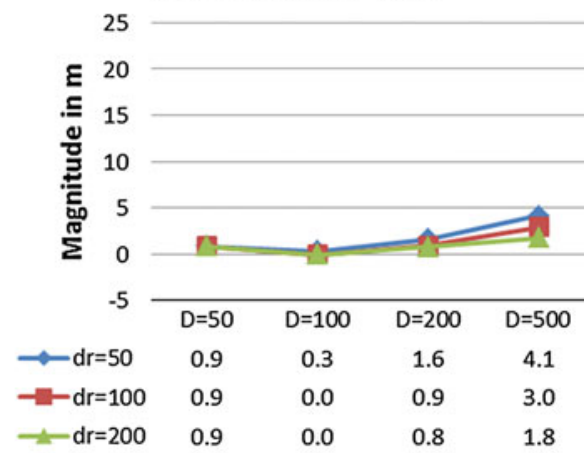

\section{Rotation about Y Axis}

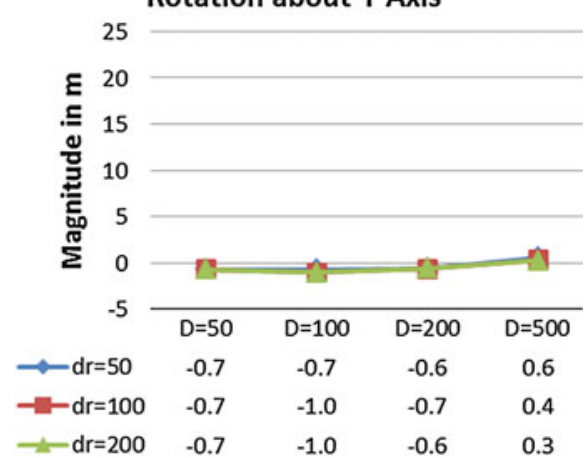

Rotation about Z Axis

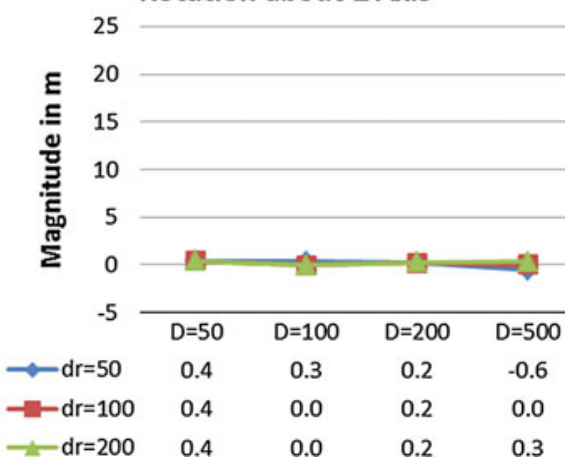


Fig. 3 continued
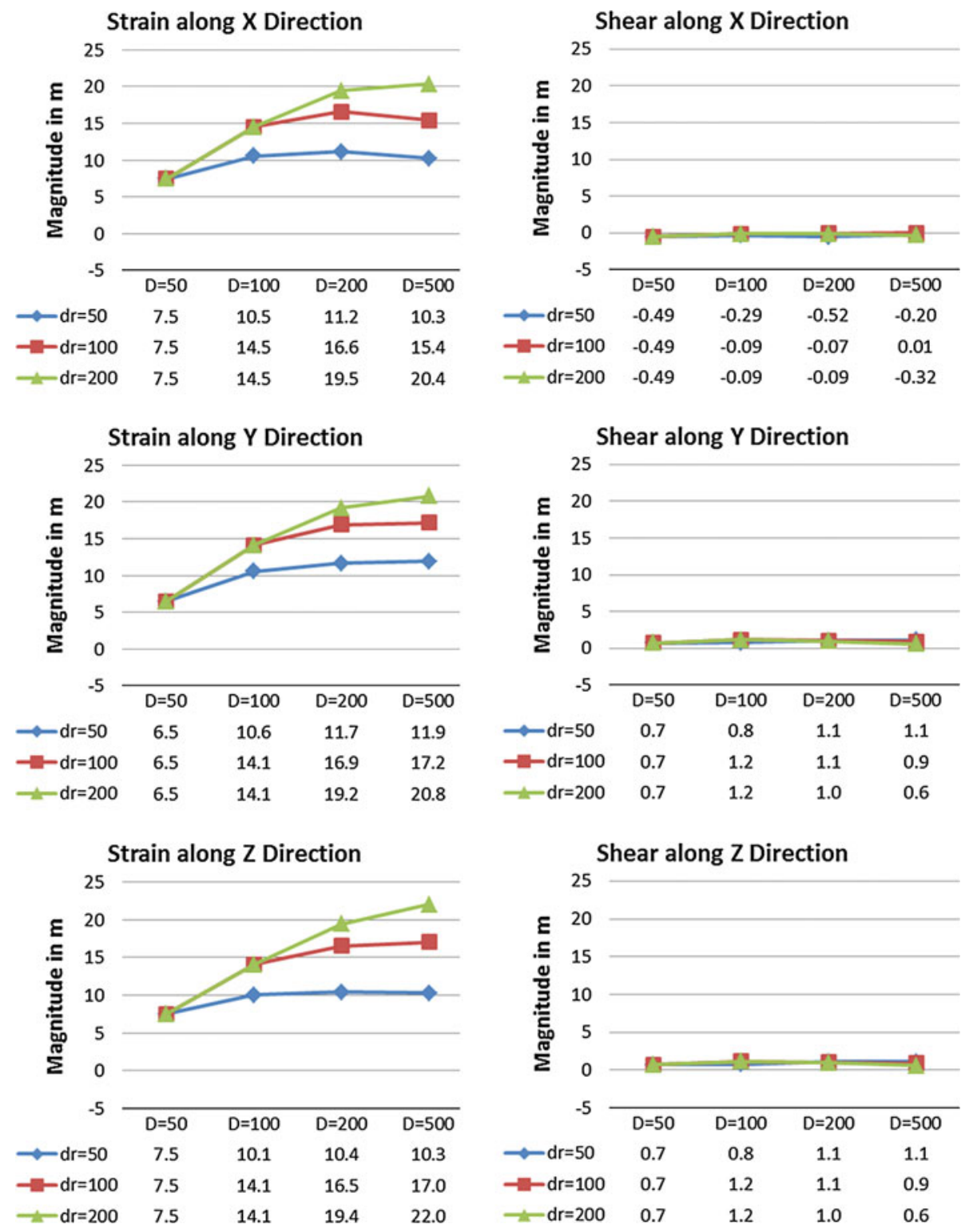